\title{
Influence of Long-Term Exposure to an Air-conditioned Environment on the Diurnal Cortisol Rhythm
}

\author{
Tomoko Ueno and Tadakatsu Ohnaka \\ Department of Living Environmental Science, Fukuoka Women's University
}

\begin{abstract}
In the present study, the influence of the long-term use of air-conditioning in summer on the cortisol rhythm was examined by measuring the rhythm in subjects who had been exposed to air-conditioning for a short [S] or long [L] time. Investigations were conducted twice in July and September. Atmospheric temperature and relative humidity near the subjects were measured for three days in each season. Saliva samples for cortisol analysis were collected every 2 hours during the daytime beginning at $8: 00 \mathrm{~h}$ with subsequent sampling times at 10:00, 12:00, 14:00, 16:00, 18:00, 20:00 and $22: 00 \mathrm{~h}$. A questionnaire on sleep and duration of airconditioning use was also undertaken. Ambient mean temperature was higher in the $\mathrm{S}$ group (mean $\pm \mathrm{SD}$; $30.8 \pm 1.2^{\circ} \mathrm{C}$ in July, $28.0 \pm 0.8^{\circ} \mathrm{C}$ in September) than in the $\mathrm{L}$ group $\left(28.0 \pm 1.2^{\circ} \mathrm{C}\right.$ in July, $27.3 \pm 1.0^{\circ} \mathrm{C}$ in September) $(p<0.01)$, while mean relative humidity did not differ. There were no differences in bedtime, waking time and sleeping hours either between groups or months. Diurnal patterns of salivary cortisol rhythm in July and September were similar in the $\mathrm{S}$ group, but the $\mathrm{L}$ group had a delayed rise of morning cortisol secretion in September compared with July. These results suggest that long-term exposure to an air-conditioned environment might adversely affect the human cortisol rhythm. J Physiol Anthropol 25(6): 357-362, 2006 http://www.jstage. jst.go.jp/browse/jpa2
\end{abstract}

[DOI: $10.2114 /$ jpa2.25.357]

Keywords: cortisol, diurnal rhythm, air-conditioning, thermal stress

\section{Introduction}

Cortisol is the principal hormonal product of the hypothalamic-pituitary-adrenal (HPA) axis in humans. It affects glucose production from protein, fat metabolism, inflammatory responses, vascular responsiveness, the central nervous system, immune functioning, and so on (Chrousos and Gold, 1998; Heim et al.; 2000; McEwen, 1998). In most humans, there is a brisk increase of cortisol following waking, and the peak level is reached about 30 min later (Kunz-Ebrecht et al., 2004; Wüst et al., 2000). In the absence of external stimuli, cortisol levels decrease throughout the day (Ice et al., 2004). Its high early morning level is considered to help sustain the energy available for action and stimulate the appetite for carbohydrate intake (Smyth et al., 1997). It is thought that cortisol level is a useful marker of HPA axis activity, and several recent pieces of research have demonstrated individual variation in diurnal cortisol patterns (Ice et al., 2004; Smyth et al., 1997; Stone et al., 2001).

In addition to its circadian rhythm, the increase in cortisol in response to stressors establishes it as one of the stress-related hormones (Dahlgren et al., 2004; Miluk-Kolasa et al., 1994; Uedo et al., 2004). Although increased cortisol secretion is considered to be an adaptive mechanism against environmental stressors (by supporting energy mobilization), chronic elevation of cortisol can lead to several disorders, such as depression, immuno-suppression, cardiovascular disease, diabetes, and osteoporosis (Deuschle et al., 1998; Ice et al,. 2004; Meaney et al., 1991; Yehuda et al., 1991). Cortisol is also observed to be a sensitive index of heat stress (Folleniius et al., 1982). Several workers have measured cortisol levels to study the influences of an extremely hot environment (Folleniius et al., 1982; Vangelova et al., 2002). However, no other studies of cortisol rhythms concerning the long-term thermal stress under regular environment (e.g. heat of summer and/or conditions under long-term use of air-conditioning) have appeared in the literature. Therefore, this study was conducted to investigate the influences on diurnal salivary cortisol levels of the long-term use of air conditioning in summer. We investigated individuals' ambient temperature and relative humidity and their cortisol rhythm in the early summer and then measured these variables again in the late summer after subjects had spent either a long or a short time in an environment which was air-conditioned.

\section{Methods}

\section{Subjects}

Initially, we interviewed volunteers who were students in 
Fukuoka Women's University about their exposure to airconditioning in the summer, and we selected from those who had been exposed for a short or long time. As a result, 17 healthy female Japanese students (aged 20 to 23 years) participated in the present study. The subjects received verbal and written instructions about this field study and gave informed consent.

\section{Procedures}

The experiments were conducted in the middle of July and September. Subjects carried thermometers (Thermo-Recorder RS-11, Espec) for three consecutive days while performing their normal daily activities, so that ambient temperature and relative humidity could be measured at two-minute intervals. For each of the two months of study, saliva samples for cortisol analysis were collected every two hours from 8:00 h to 22:00 h during the course of a single day that excluded the time of menstruation (because some subjects reported periodic taking of analgesics during that period).

A questionnaire was also given on the days of sampling the saliva. The questionnaire items were exposure to airconditioning, bedtime, waking time and quality of sleep (ranging from 1, slept well, to 5, couldn't sleep at all). In addition, age, body height and weight were asked in the questionnaire given in July, and the use of air-conditioning during August was also questioned in September. Subjects were asked to undertake their usual daily activities during the experimental days.

\section{Cortisol measurements}

Saliva samples were used to assess the cortisol levels; they have been reported to correlate with serum and plasma cortisol (Umeda et al., 1981; Kirschbaum and Hellhammer, 1994; Wedekind et al., 2002), and collection of saliva is relatively non-invasive and suited to studies under field conditions.

Subjects were instructed in saliva collection using saliva collection tubes "Salivettes" (Sarstedt, Rommelsdorf, Germany) prior to the experimental days. Subjects were instructed to store the saliva samples in domestic freezers until returning them to the laboratory (up to three days after collection). The saliva samples were subsequently stored at $-20^{\circ} \mathrm{C}$ in the laboratory until thawed for assay. The amount of cortisol secretion was determined with the salivary cortisol ELISA kit (DRG Instruments GmbH, Germany).

On days of saliva sampling, subjects were asked to avoid the intake of caffeine, alcohol and medicine both during the daytime and the previous night. They were also asked not to eat, drink or brush their teeth for the $90 \mathrm{~min}$ before sampling times, to avoid affecting cortisol levels and/or contaminating the samples (Federenko et al., 2004; Ice et al., 2004; KunzEbrecht et al., 2004; Lovallo et al., 1996; Rosmond and Bjorntorp, 1998; Shirtcliff et al., 2001). All subjects were nonsmokers.

In addition, to verify compliance with the protocol, subjects filled in a diary to record the time they took each sample as well as the time and contents of any meals they had eaten on days of saliva sampling. Subjects also recorded any physical or mental stresses they had experienced.

\section{Data analysis}

Two-way analysis of variance (ANOVA) was used to examine any differences in ambient temperature, relative humidity and cortisol between the times of day and groups, and two-way repeated measures ANOVA was used to investigate differences between the times of day and months. Any differences with the main effects were then investigated using Student's $t$-test. Statistical significance was accepted at $p<0.05$.

\section{Results}

Age, physical characteristics and results of the sleep questionnaire by group

Based on the results of the questionnaire, subjects were divided into two groups; those who had used air-conditioning in July for less than 4 hours a day ( $n=8$, short-time [S] group) and those who used it for more than 6 hours $(n=9$, long-time [L] group). Table 1 summarizes the results from the questionnaire. Apart from the use of air-conditioning, the groups did not differ in any variable. Concerning the amount of exposure to air-conditioning, there were significant differences between the groups in each month $(p<0.05)$, i.e. the $\mathrm{L}$ group used it for longer than the $\mathrm{S}$ group. The $\mathrm{L}$ group had significantly different exposures between July and September (paired $t$-test, $p<0.01$ ), and August and September

Table 1 Age, physical characteristics and results of sleep questionnaire by group

\begin{tabular}{lcc}
\hline & S group $(n=8)$ & L group $(n=9)$ \\
\hline Age & $21.0 \pm 0.8 \mathrm{yrs}$ & $21.4 \pm 1.0 \mathrm{yrs}$ \\
Height & $156.1 \pm 5.7 \mathrm{~cm}$ & $158.9 \pm 4.4 \mathrm{~cm}$ \\
Weight & $47.8 \pm 2.1 \mathrm{~kg}$ & $49.1 \pm 3.4 \mathrm{~kg}$ \\
BMI & $19.7 \pm 1.7$ & $19.5 \pm 1.1$ \\
July & & \\
Use of air-conditioning & $2.1 \pm 1.0$ hours/day & $11.4 \pm 4.5$ hours/day \\
$\quad$ within a week** & & \\
Bedtime & $1: 06 \mathrm{~h} \pm 90 \mathrm{~min}$ & $1: 11 \mathrm{~h} \pm 63 \mathrm{~min}$ \\
Waking time & $7: 19 \mathrm{~h} \pm 26$ min & $7: 15 \mathrm{~h} \pm 37$ min \\
Sleeping hours & $6.0 \pm 1.5$ hours & $6.3 \pm 0.7$ hours \\
Quality of sleep & $2.1 \pm 1.2$ & $1.8 \pm 1.0$ \\
September & & \\
Use of air-conditioning & $1.7 \pm 1.1$ hours/day & $14.0 \pm 5.5 \mathrm{hours} /$ day \\
in August** & & \\
Use of air-conditioning & $1.3 \pm 1.6$ hours/day & $4.3 \pm 3.2$ hours/day \\
$\quad$ within a week* & & \\
Bedtime & $0: 49 \mathrm{~h} \pm 68 \mathrm{~min}$ & $1: 00 \mathrm{~h} \pm 47 \mathrm{~min}$ \\
Waking time & $7: 14 \mathrm{~h} \pm 45$ min & $7: 37 \mathrm{~h} \pm 40 \mathrm{~min}$ \\
Sleeping hours & $6.4 \pm 0.9$ hours & $6.6 \pm 0.5$ hours \\
Quality of sleep & $2.0 \pm 0.9$ & $1.7 \pm 1.0$ \\
\hline & &
\end{tabular}

** $p<0.01, * p<0.05$, respectively, Student's $t$-test, comparing values for each group. 


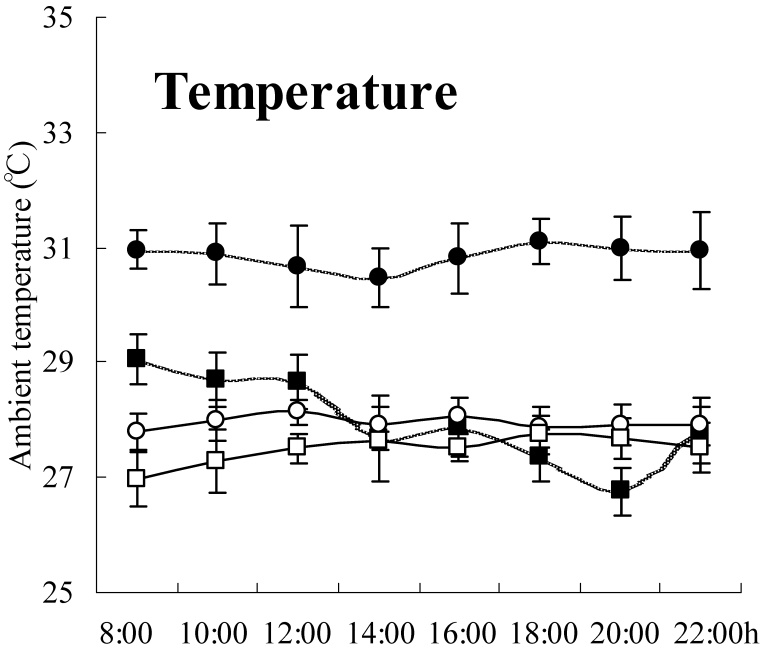

Time of day

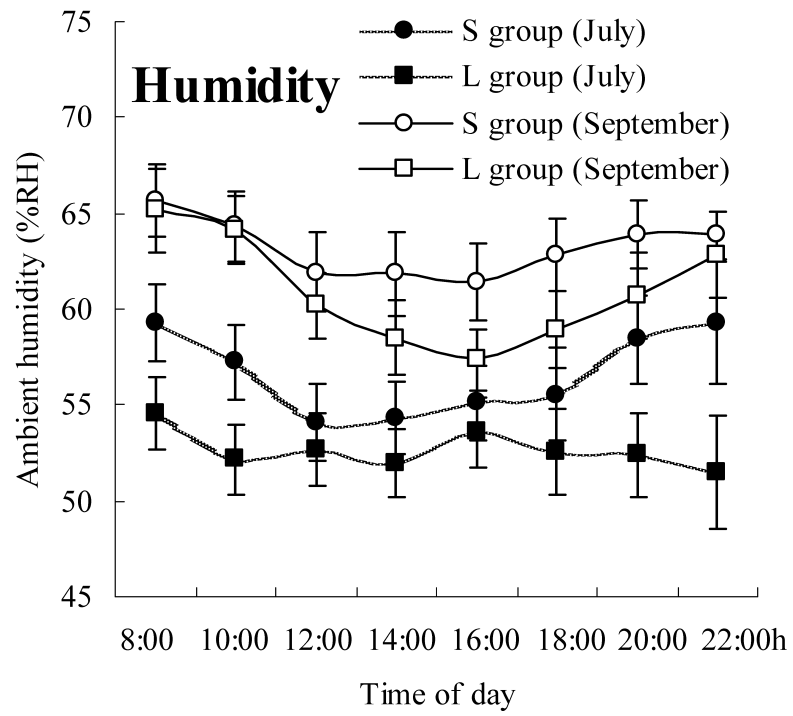

Fig. 1 Ambient temperature and relative humidity surrounding subjects in July and September in each group. Values are means \pm SE.

(paired $t$-test, $p<0.01$ ). Sleep rhythm and the quality of sleep were not influenced by the season in spite of the different amount of use of air-conditioning.

\section{Ambient temperature and relative humidity surrounding subjects}

The average of ambient temperature was higher in the $\mathrm{S}$ group (mean $\pm \mathrm{SD} ; 30.8 \pm 1.2^{\circ} \mathrm{C}$ in July, $28.0 \pm 0.8^{\circ} \mathrm{C}$ in September) than the L group $\left(28.0 \pm 1.2^{\circ} \mathrm{C}\right.$ in July, $27.3 \pm$ $1.0^{\circ} \mathrm{C}$ in September) in both months $(p<0.01)$. Figure 1 shows daytime ambient temperature and relative humidity. ANOVA of ambient temperature revealed significant differences between months in the $\mathrm{S}$ group $(p<0.01)$ and between the groups in July $(p<0.01)$, and a significant interaction between the times and groups in July $(p<0.05)$. The average relative humidities were $56.9 \pm 5.8 \%$ in July, $63.5 \pm 5.1 \%$ in September for the $\mathrm{S}$ group and $52.7 \pm 5.5 \%$ in July, $61.7 \pm 5.5 \%$ in September for the $\mathrm{L}$ group. Two-way ANOVA revealed significant differences between the months in each group ( $\mathrm{S}$ group: $p<0.05$; L group: $p<0.01$ ), and a significant interaction between the times and months in the L group $(p<0.01)$.

\section{Rhythms and levels of salivary cortisol secretion}

As indicated by inspection of the diary, all subjects complied with the protocol; with regard to cortisol sampling, all samples were taken within $10 \mathrm{~min}$ of the times required by the protocol. Although three subjects reported physical or mental stresses in the afternoon (two in July and one in September), there was no effect upon cortisol levels at this time or thereafter. Figure 2 shows the results of salivary cortisol analysis. The maximum values of cortisol secretion were not significantly different between the two groups or months (Table 2). The $\mathrm{S}$ group had typical rhythms in both July and September. In July, there were no significant differences between the two groups. In September, however, whereas cortisol levels were highest at 08:00 h and decreased thereafter in the $\mathrm{S}$ group, the $\mathrm{L}$ group had peak levels at 10:00 h. Two-way ANOVA of cortisol levels revealed a significant interaction between the times and groups in September $(p<0.05)$; cortisol levels of the L group were significantly lower at 08:00 $\mathrm{h}(p<0.05)$ and higher at 10:00 $\mathrm{h}$ $(p<0.05)$ than corresponding values from the $\mathrm{S}$ group.

\section{Discussion}

The $\mathrm{S}$ and $\mathrm{L}$ groups were different in their exposure to airconditioning, mean ambient temperature and in their cortisol patterns. There were no differences in age, physical characteristics, mean relative humidity, bedtime, waking time, sleeping hours and quality of sleep between groups.

Previous studies have showed higher cortisol levels in workers under extreme hot environments such as in a glass manufacturing unit (Folleniius et al., 1982; Vangelova et al., 2002). Although the $S$ group was exposed to a hotter environment than the L group, basal levels of salivary cortisol rhythm during the daytime did not change or become unstable in either July or September in the S group. Therefore, it can be considered that seasonal variations of ambient temperature and relative humidity in these months did not increase cortisol secretion during the daytime.

In several recent studies, the cortisol response on awakening, i.e. the change in cortisol levels that typically occur 20-40 min after waking up in the morning, has been measured (Wüst et al., 2000a; Wüst et al., 2000b; Kunz-Ebrecht et al., 2004; Williams et al., 2005). These studies found that the magnitude of the morning cortisol level was related to psychosocial stress; increases of cortisol levels in the morning were greater on work days than weekend days (Kunz-Ebrecht 


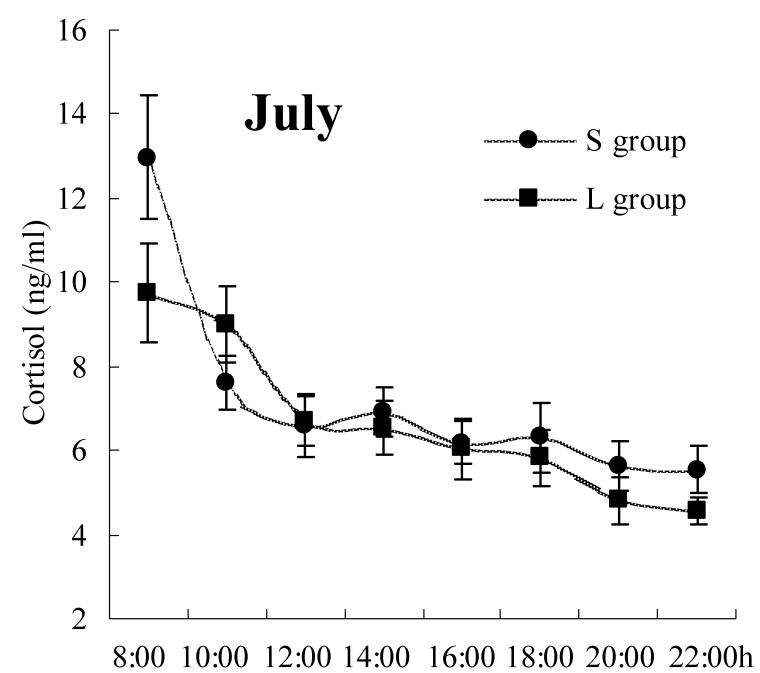

Time of day

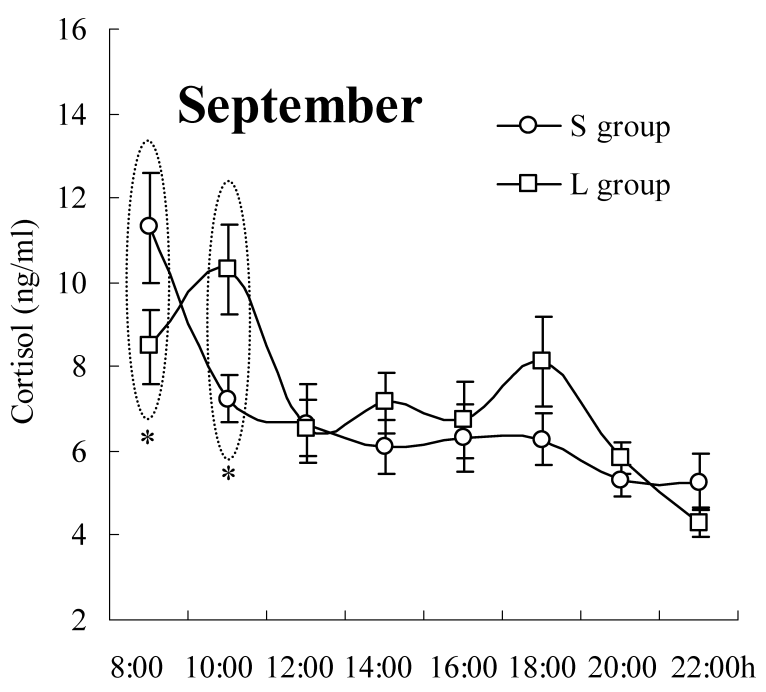

Time of day

Fig. 2 Cortisol rhythms from $\mathrm{S}$ and $\mathrm{L}$ groups in July and September.

Values are means \pm SE. $* p<0.05$, Student's $t$-test, comparing values for between $\mathrm{S}$ and $\mathrm{L}$ groups.

Table 2 The maximum values of cortisol measurement in each season and group

\begin{tabular}{lcc}
\hline & S group $(n=8)$ & L group $(n=9)$ \\
\hline July & $12.97 \pm 4.10,8: 00 \mathrm{~h}$ & $9.76 \pm 3.53,8: 00 \mathrm{~h}$ \\
September & $11.30 \pm 3.67,8: 00 \mathrm{~h}$ & $10.32 \pm 3.20,10: 00 \mathrm{~h}$ \\
\hline
\end{tabular}

mean $\pm \mathrm{SD}(\mathrm{ng} / \mathrm{mL})$, time of day

et al., 2004), and were enhanced under conditions of chronic psychosocial stress (Wüst et al., 2000b). By contrast, Bailey and Heitkemper (2001) reported that the time of peak morning cortisol rhythms occurred later in evening chronotypes than in morning chronotypes, and Aeschbach et al. (2003) reported that the cortisol maximum was related to habitual wake-up time, which occurred later in long-sleepers than in shortsleepers. In the present study, subjects were asked to continue their normal daily life during the experimental days, and sleep parameters (bedtime, waking time, sleeping hours and quality of sleep) were not significantly different between the S and L groups. Nevertheless, there were no significant differences between the two groups in July and September with regard to the morning peak levels of cortisol secretion, while cortisol levels of the L group were significantly lower at 08:00 h $(p<0.05)$ and higher at 10:00 $\mathrm{h}(p<0.05)$ in September. These data suggested that the $\mathrm{L}$ group had a relatively delayed peak time of morning cortisol secretion in September rather than an increase in amplitude. Although the current study did not measure the habitual sleep-wake rhythms in August (during the summer vacation taken by subjects), Jelinkova-Vondrasova et al. (1999) indicated that circadian phase shifts of cortisol occurred within 6 days of a shifting of the sleep period under dim light.

In conclusion, awakening imposes a burst of secretory activity from the HPA axis (Edwards et al., 2001). High early morning levels of cortisol secretion are considered to help sustain energy for activity and to stimulate the appetite for carbohydrate intake (Smyth et al., 1997), so ascribing an essential role to this morning increase. In the present study, however, the L group had a later increase in cortisol in the morning in September. These data suggest that long-term exposure to an air-conditioned environment may weaken or delay HPA axis activity, especially in the morning. The HPA axis is of major importance with regard to an organism's response to physical or psychosocial stimulation, and morning awakening should be associated with bursts of cortisol secretion (Federenko et al., 2004). The use of air-conditioning in summer seems to provide comfort and to reduce physiological stress from the summer heat, but it is also seems that large variations of ambient temperature and relative humidity between indoors and outdoors might act as environmental stressors, and might adversely affect cortisol rhythms.

Acknowledgements The authors thank Dr. Jim Waterhouse, Liverpool, UK for his kind correction of our English text. This study was supported in part by a Grant-in-Aid for Scientific Research (16107006).

\section{References}

Aeschbach D, Sher L, Postolache TT, Matthews JR, Jackson MA, Wehr TA (2003) A longer biological night in long sleepers than in short sleepers. J Clin Endocrinol Metab 88: 26-30

Bailey SL, Heitkemper MM (2001) Circadian rhythmicity of cortisol and body temperature: morningness-eveningness effects. Chronobiol Int 18: 249-261

Caufriez A, Moreno-Reyes R, Leproult R, Vertongen F, Van 
Cauter E, Copinschi G (2002) Immediate effects of an 8-h advance shift of the rest-activity cycle on 24-h profiles of cortisol. Am J Physiol Endocrinol Metab 282: E1147E1153

Chrousos GP, Gold PW (1998) A healthy body in a healthy mind - and vice versa - the damaging power of "uncontrollable" stress. J Clin Endocrinol Metab 86: $1842-1845$

Dahlgren A, Akerstedt T, Kecklund G (2004) Individual differences in the diurnal cortisol response to stress. Chronobiol Int 21: 913-922

Deuschle M, Weber B, Colla M, Depner M, Heuser I (1998) Effects of major depression, aging and gender upon calculated diurnal free plasma cortisol concentrations: a reevaluation study. Stress 2: 281-287

Edwards S, Evans P, Hucklebridge F, Clow A (2001) Association between time of awakening and diurnal cortisol secretory activity. Psychoneuroendocrinology 26: 613-622

Federenko I, Wüst S, Hellhammer DH, Dechoux R, Kumsta R, Kirschbaum C (2004) Free cortisol awakening responses are influenced by awakening time. Psychoneuroendocrinology 29: $174-184$

Follenius M, Brandenberger G, Oyono S, Candas V (1982) Cortisol as a sensitive index of heat-intolerance. Physiol Behav 29: 509-513

Heim C, Ehlert U, Hellhammer D (2000) The potential role of hypocortisolism in the pathophysiology of stress-related bodily disorders. Psychoneuroendocrinology 25: 1-35

Ice GH, Katz-Stein A, Himes J, Kane RL (2004) Diurnal cycles of salivary cortisol in older adults. Psychoneuroendocrinology 29: 355-370

Jelinkova-Vondrasova D, Hajek I, Illnerova H (1999) Adjustment of the human circadian system to changes of the sleep schedule under dim light at home. Neurosci Lett 265: 111-114

Kirschbaum C, Hellhammer KH (1994) Salivary cortisol in psychoneouroendocrine research: recent developments and applications. Psychoneuroendocrinology 19: 313-333

Kunz-Ebrecht SR, Kirschbaum C, Marmot M, Steptoe A (2004) Differences in cortisol awakening response on work days and weekends in women and men from the Whitehall II cohort. Psychoneuroendocrinology 29: 516-528

Lovallo WR, Al'Absi M, Blick K, Whitsett TL, Wilson MF (1996) Stress-like adrenocorticotropin responses to caffeine in young healthy men. Pharamacol Biochem Behav 55: 365-369

Meaney MJ, Mitchell JB, Aitken DH, Bhatnagar S, Bodnoff SR, Iny LJ, Sarrieau A (1991) The effects of neonatal handling on the development of the adrenocortical response to stress: Implications from neuropathology and cognitive deficits in later life. Psychoneuroendocrinology 16: 85-103

Miluk-Kolasa B, Obminski Z, Stupnicki R, Golec L (1994) Effects of music treatment on salivary cortisol in patients exposed to pre-surgical stress. Exp Clin Endocrinol 102: $118-120$
Rosmond R, Bjorntorp P (1998) Endocrine and metabolic aberrations in men with abdominal obesity in relation to anxio-depressive infirmity. Metabolism 47: 1187-1193

Shirtcliff EA, Granger DA, Schwartz E, Curran MJ (2001) Use of salivary biomarkers in biobehavioral research: cottonbased sample collection methods can interfere with salivary immunoassay results. Psychoneuroendocrinology 26: $165-173$

Smyth JM, Ockenfels MC, Gorin AA, Catley D, Porter LS, Kirschbaum C, Hellhammer DH, Stone AA (1997) Individual differences in the diurnal cycle of cortisol. Psychoneuroendocrinology 22: 89-105

Steptoe A, Kunz-Ebrecht S, Owen N, Feldman PJ, Willemsen G, Kirschbaum C, Marmot M (2003) Socioeconomic status and stress-related biological responses over the working day. Psychosom Med 65: 461-470

Stone AA, Schwartz JE, Smyth J, Kirschbaum C, Cohen S, Hellhammer D, Grossman S (2001) Individual differences in the diurnal cycle of salivary free cortisol: a replication of flattened cycles for some individuals. Psychoneuroendocrinology 26: 295-306

Uedo N, Ishikawa $\mathrm{H}$, Morimoto $\mathrm{K}$, Ishihara $\mathrm{R}$, Narahara $\mathrm{H}$, Akedo I, Ioka T, Kaji I, Fukuda S (2004) Reduction in salivary cortisol level by music therapy during colonoscopic examination. Hepatogastroenterology 51: 451-453

Umeda T, Hiramatsu R, Iwaoka T, Shimada T, Miura F, Sato T (1981) Use of saliva for monitoring unbound free cortisol levels in serum. Clin Chim Acra 110: 245-253

Vangelova K, Deyanov Ch, Velkova D, Ivanova M, Stanchen V (2002) The effect of heat exposure on cortisol and catecholamine excretion rates in workers in glass manufacturing unit. Cent Eur J Public Health 4: 149-152

Wedekind D, Bandelow B, Broocks A, Hajak G, Ruther E (2000) Salivary, total plasma and plasma free cortisol in panic disorder. J Neural Transm107: 831-837

Williams E, Magid K, Steptoe A (2005) The impact of time of waking and concurrent subjective stress on the cortisol response to awakening. Psychoneuroendocrinology 30: 139-148

Wüst S, Wolf J, Hellhammer DH, Federenko I, Schommer N, Kirschbaum C (2000a) The cortisol awakening responsenormal values and confounds. Noise Health 7: 77-85

Wüst S, Federenko I, Hellhammer DH, Kirschbaum C (2000b) Genetic factors, perceived chronic stress, and the free cortisol response to awakening. Psychoneuroendocrinology 25: 707-720

Yehuda R, Lowy MT, Southwick SM, Shaffer D, Giller EL Jr (1991) Lymphocyte glucocorticoid receptor number in posttraumatic stress disorder. Am J Psychiatry 148: 499-504

Received January 17, 2006

Accepted August 31, 2006

Correspondence to: Tomoko Ueno, Department of Living Environmental Science, Fukuoka Women's University, 1-1-1 Kasumigaoka, Higashi-ku, Fukuoka 813-8529, Japan 
Phone: +81-92-661-2411

Fax: +81-92-661-2415

e-mail: ueno@fwu.ac.jp 